\title{
El Parque de los Colores
}

Alfonso Gómez Profesor, Escuela de Arquitectura, Universidad Diego Portales

La revisión que un arquitecto chileno hace de este proyecto de Miralles se detiene en aspectos fundamentales de la arquitectura contemporánea: vínculos declarados con el arte, indiscutible dimensión social de proyecto y coexistencia de referentes tan distantes como Miguel Angel y el graffiti urbano.
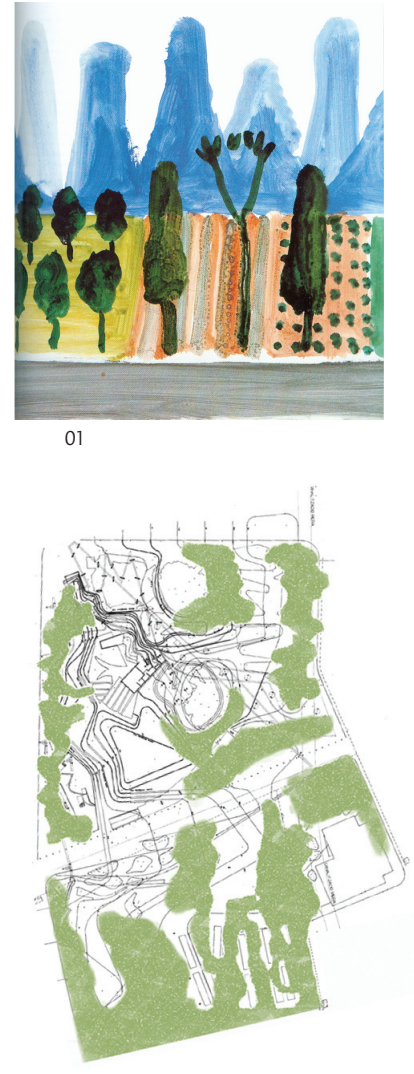

04

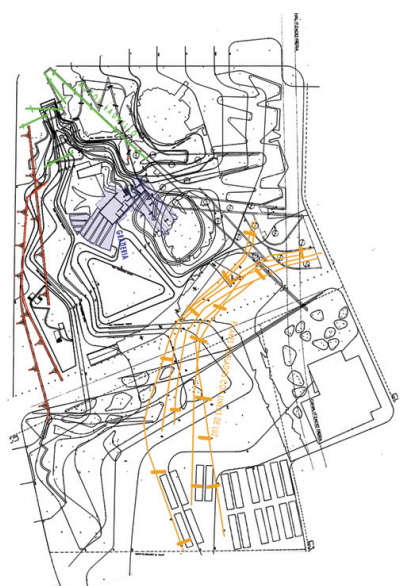

07
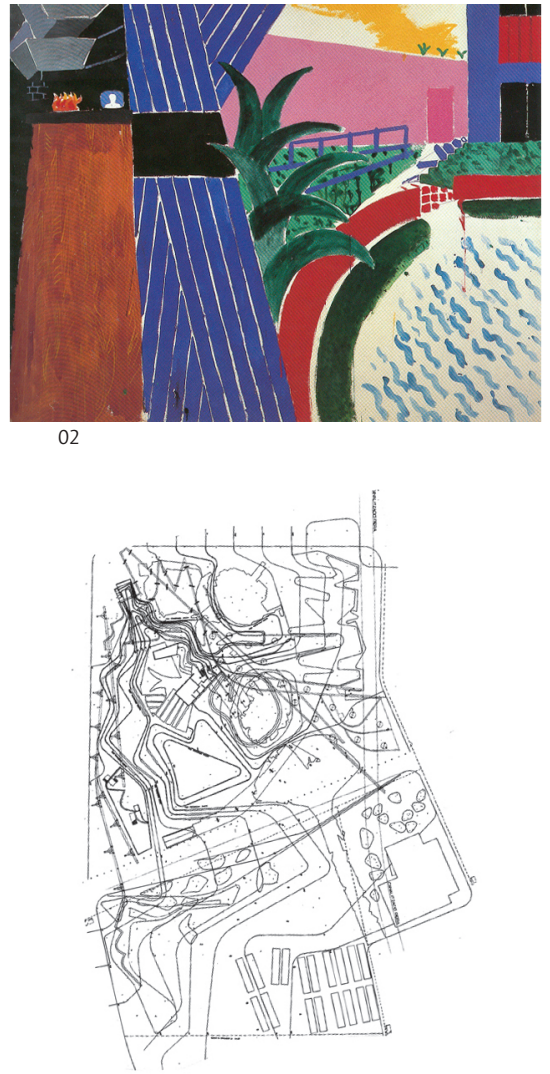

05

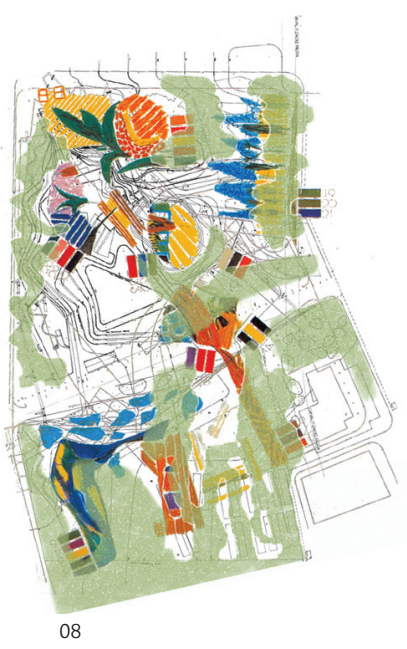

A Chilean architect reviews this project by Enric Miralles revealing some relevant, current topics of contemporary architecture: explicit links with art, design's social dimension and distant but converging references, such as Michelangelo and urban graffiti.
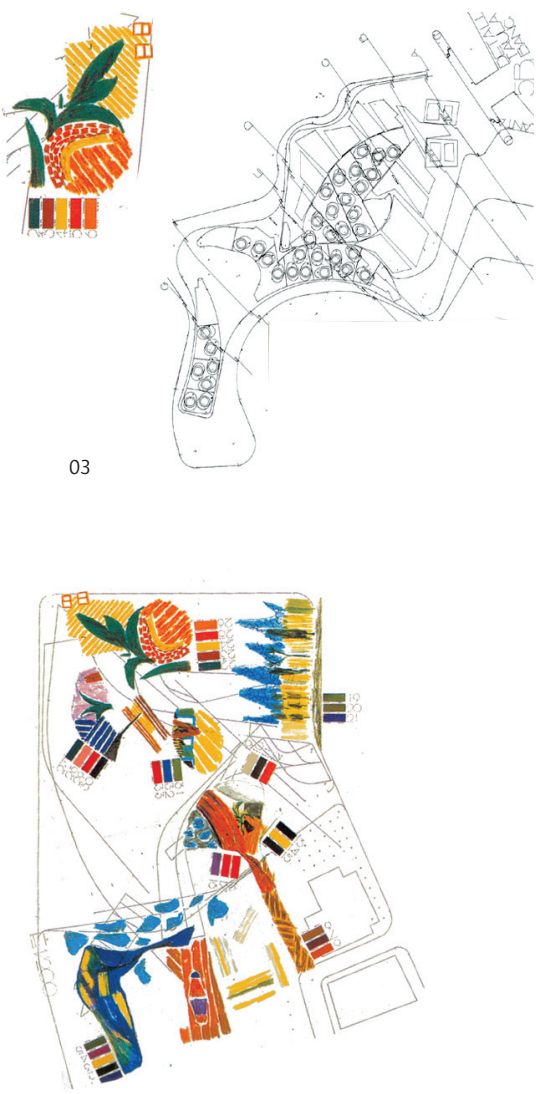

06

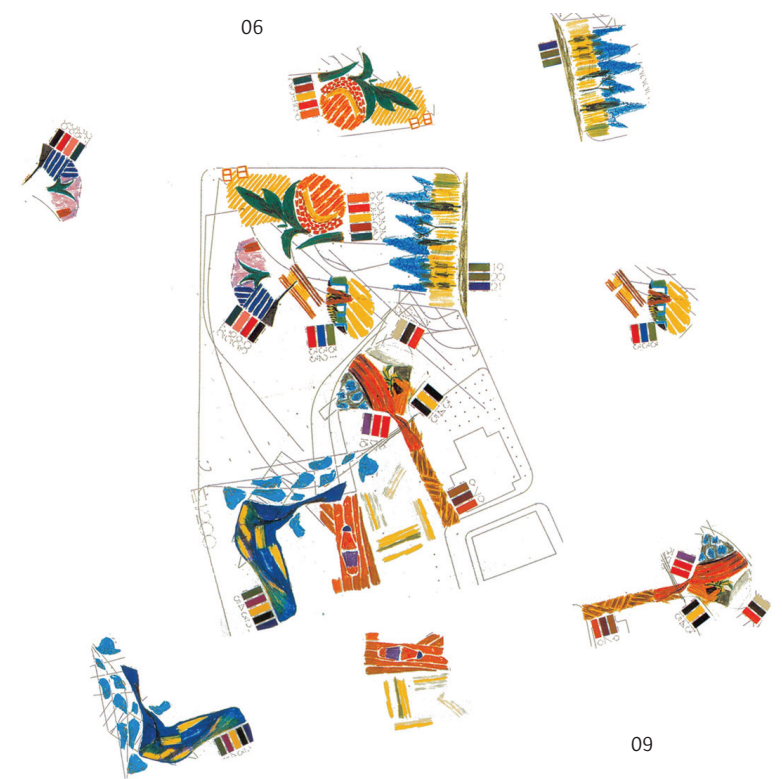


'En referencia al proyecto de las instalaciones de Tiro con Arco en Barcelona. Diseño Interior № 11, enero 1992.

01 David Hockney. Plants, trees, fields and mountains. Kweinlin, China, 1981

02 David Hockney. Terrace Hollywood Hill house with banana tree 1982

03 Fulla i flor. pavimentos, maceteros, asientos

04 Planta, masa de árboles proyectada

05 Planta, topografía y curvas de nivel

06 Planta, pavimentos de colores

07 Planta, curvas de nivel + estructuras superpuestas

08 Planta, superposición sombras, colores, líneas

09 Argumento narrativo, la metáfora del contenido

10 Aldo van Eyck. Área de juegos en Bertelmanplein,

Ámsterdam, 1947

11 Vista del parque hacia el poniente

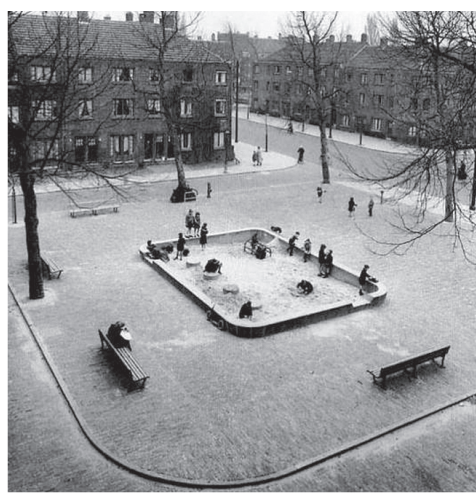

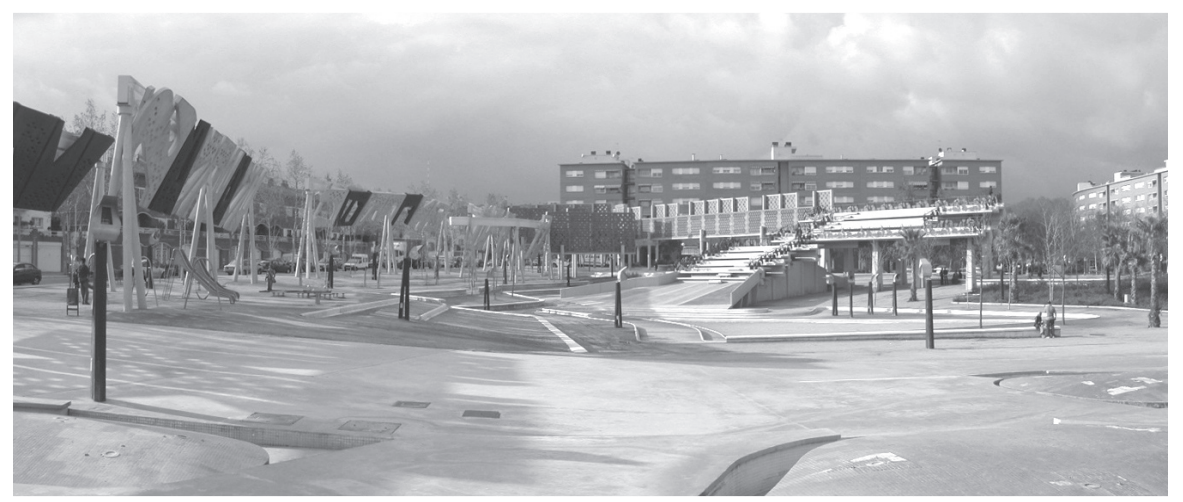

"El Parque de los Colores en Mollet del Vallès, una localidad del cinturón industrial de Barcelona, al noroeste de la capital catalana. Elaborado entre 1992 y 1995 y realizado entre 1995 y 2001, el proyecto surge en medio de los barrios residenciales de Santa Rosa y Plana Lledó, en un área marginal, donde a la ausencia de cualidades específicas del contexto le correspondía, en el momento de la asignación del encargo, una fuerte expectativa social de la comunidad" (De Michelis y Scinemi, 2002).

"No creo que se pueda estar por delante del trabajo de uno, tirando de él, sino que de alguna manera el propio trabajo va dirigiendo las cosas a través de pequeñas desviaciones”. Enric Miralles

LA REPRESENTACIÓN VIRTUAL DE LO SOCIAL. LOS ESCENARIOS DE LA ARQUTTECTURA / El Parque de los Colores, inserto en la obra total de Enric Miralles, redefine los parques urbanos, cargando a este trozo de ciudad con formas simbólicas y contenido social, constatando el cruce de miradas entre artista y arquitecto, identificando una manera de redescribir la arquitectura como una actitud -perdida entre nosotros- que nos hace "ver la realidad de una manera singular, desde una perspectiva imposible hasta el momento” (Muntañola, 2004).

Este lugar común es traído, paradójicamente, de abstracciones producto de lugares inventados -un paisaje ideal- (Márquez y Levene, 2000), abstracciones sensibles al uso específico -movimiento y emoción-(Ackerman, 1997), puestas a dialogar con las trazas descubiertas en el lugar.

"Un nuevo orden geométrico y espacial, irregular pero preciso, que entra en tensión con las leyes del lugar existente"1.

AproXimaciones a la ARQUiTECTURA. HACER REFERENCIA AL MOMENTO EN QUE LA ARQUITECTURA ES PENSADA / Un proyecto es también una invención teórica, es la dialéctica entre virtualidad y realidad, es una aproximación al origen de la forma arquitectónica (Arranz, 1989).

Las capas de información utilizadas forman el argumento de esta obra, veremos en cada una de estas fuentes experimentales el sentido poético de su narrativa (Ricoeur, 2003). Miralles usa estas capas para dar un guión al parque, para imaginar los fragmentos de todas las aristas del proyecto, y yo las utilizaré para "mostrar el tipo de material que está alrededor de las cosas" (Massad y Guerrero, 2001).

Veremos este proyecto desde la perspectiva de lo pensado, lo que estaba sobre la mesa del arquitecto, entendiendo la representación gráfica como otra capa de información, como "un modo de anotar recuerdos, de poner juntos los materiales que forman una obra de arquitectura... a partir de ese concepto he desarrollado el tema de la representación deformante, que recoge solamente visiones parciales, mientras que la construcción del proyecto debe todavía desarrollarse" (Lahuerta, 1996), estas parcialidades han sido descontextualizadas, pero aquí están como "documentos de un pensamiento" (Miralles, 1992) y que tienen algo de su lugar original.
I. Contexto y ambiente: Aldo Van Eyck / La percepción global del Parque de los Colores, como hecho y encargo urbano, se podría entender por medio de una parte de la obra del arquitecto holandés Aldo Van Eyck. Esa parte corresponde a sus primeros trabajos (entre 1947 y 1955) en la etapa de reconstrucción de los espacios públicos de Ámsterdam después de la Segunda Guerra Mundial.

El contexto (la ciudad marginal), el tiempo (el movimiento) y el carácter lúdico (la festividad) son los temas primordiales que desarrolló Van Eyck en estos nuevos lugares infantiles. El espíritu de interpretar o representar un trozo de ciudad marginal y recomponerla, utilizando como dato importante lo que había, pero redescubierto, cambia la energía y el espíritu de ese lugar deteriorado.

Como Van Eyck, con pocos pero profundos movimientos, aceptando un muro ciego y un sitio eriazo como algo arraigado a la memoria de los habitantes, se logra una inversión de significado, una re-descripción de la estética de un parque.

Ambos proyectos, "dentro de sus límites, animan a sus ocupantes al desarrollo de su imaginación y al uso de su energía” (Strauven, 1998).

II. TRAZAS: LA FUERZAS DE LA CIUDAD / Las primeras modificaciones del lugar original del Parque de los Colores nacieron de sutiles incentivos provocados por situaciones del contexto, que provocaron posibilidades de acción. Estas líneas de fuerza, que yo llamaría trazas del lugar, son tres líneas o gestos reconocibles que, aprovechando los propios bordes del lugar existente, pero deformados, se transforman en los nuevos límites propuestos. "Ese trazo adquiere la cualidad de acción" (Arranz, 1989).

"Una forma que, en su proceso de gestación, estará sometida a todas las fuerzas del entorno, a todas las presiones contextuales que proceden desde el exterior, pero que necesitará también del impulso generativo interno, de modo que este proceso de gestación de la forma esté basado en sus propios requerimientos y parámetros y sea guiado por pautas marcadas desde dentro" (Cortés, 1998).

III. Topografía social / "Este suelo construido como un mapa figurativo de diferentes situaciones cotidianas, un paseo, un jardín... es definido en torno a una topografía precisa que procura diferentes rutas y funciones públicas" (Márquez y Levene, 2000).

La topografía se plantea como un suelo unitario, formado por terrazas irregulares de tierra o pasto como líneas blancas y sinuosas que acusan los desniveles. La topografía artificial, planteada en el proyecto, transforma un sitio plano en un anfiteatro de suave desnivel.

El lugar se entiende ahora como "una estratificación de elementos aparentemente incoherentes, que al acumularse -como las cotas-revelan la complejidad del lugar en el tiempo. La idea de que el entorno estaba lejos de ser un lugar coherente y socialmente aceptado, 'dio pie para excavar', metafórica y realmente, en el sitio para descubrir y dar forma al presente más que reconstruir el pasado desaparecido o no aceptado" (De Michelis y Scinemi, 2002). 


\section{Conversación del autor con Josep Mías, enero 2004. \\ ${ }^{3}$ Texto de Enric Miralles en la Introducción a Lahuerta, Juan José. Documentos de Arquitectura Enric Miralles, Obras y Proyectos. Editorial Electa, Milán, 1996. \\ ${ }^{4}$ Ibid. \\ ${ }^{5}$ Carmen Pinós, frase referida a la inspiración de su obra y a su pos. terior desarrollo. Charla ETSAB, Barcelona, diciembre de 2003 \\ ${ }^{6}$ Conversación del autor con Josep Mías, enero 2004.}
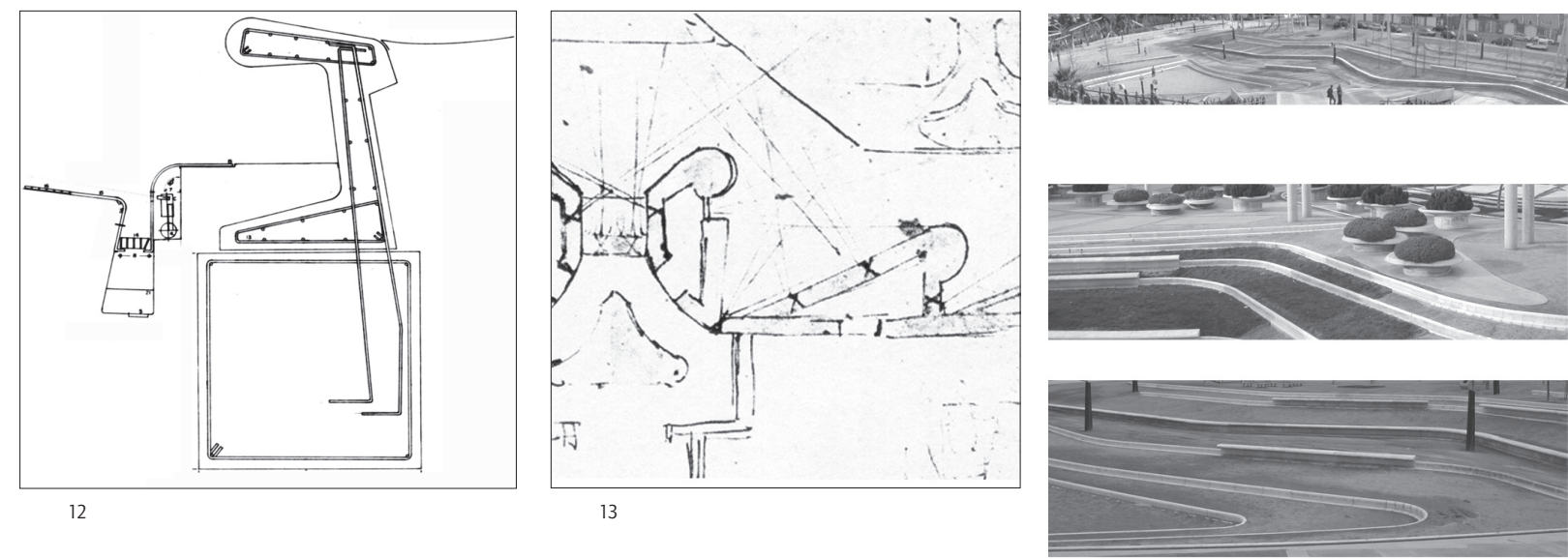

Miguel Ángel, estudio de molduras y fortificaciones: "Miralles estudia dibujos de Miguel Ángel para el diseño de la pieza de hormigón que 'soporta' el desnivel de la topografía artificial" ${ }^{2}$. La pieza de hormigón prefabricado confina el borde de la tierra o del pasto, es un asiento y su zapata sirve de pavimento a la parte inferior. "Este relieve es el lugar privilegiado donde esconder un pensamiento recogido" (Arranz, 1989).

Miralles tenía un especial interés en la capacidad del dibujo como "instrumento abstracto, como anotación del pensamiento y como indicación para la

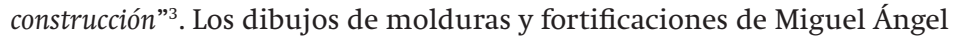
ayudaron a encontrar la lógica de esta grada, que podría entenderse como una moldura fuera de escala.

La cercanía de Miralles con el trabajo de Miguel Ángel podría tener sus raíces en que Miguel Ángel proclamaba siempre ser escultor, no arquitecto, y podría ser una clave para entender sus edificios y diseños, "concebidos como si las masas constructivas fueran formas orgánicas y, como estatuas, susceptibles de ser moldeadas y talladas, de expresar movimiento, de crear sinfonías de luz, sombra y textura" (Ackerman, 1997). Ésta bien podría ser una descripción de la obra de Miralles.

IV. Los COLOREs / El nombre del parque nace de los colores de la maqueta que Miralles presentó al Ayuntamiento de Mollet. "Nunca lo he comentado, pero a lo mejor os habéis dado cuenta: ilos dibujos en planta del Parque del Mollet son copiados de Hockney! iPero clavado!” (Márquez y Levene, 2000).

Entre Miralles y Hockney hay una fuerte conexión, es un personaje del que ha desarrollado varias ideas; la más evidente, sus representaciones del collage en esas fotos múltiples que toman el tiempo de las cosas y lo registran, que le sirven para "fijar un pensamiento" como "instantes interrumpidos de un proyecto" 4 .

Extracto del texto de un viaje a China hecho por David Hockney en mayo de 1981, en comisión de trabajo para realizar un libro de cooperación británica, El Diario de China.

"Como el viaje fue organizado en la medida que nos movíamos... ideé un método para dibujar rápido o de memoria... Recuerdo que llegando a Kweinlin y me sorprendí... saqué tinta de color marrón y papel e hice unas grandes manchas, que eran las montañas que estaba viendo... es como si los niños hubieran dibujado las montañas.

Al visitar Cantón... le pregunté al Sr. Lin qué hacía la gente por las tardes... Me dijo que había un parque cultural... fuimos a verlo... era como un parque de diversiones, había roller-skaters, toboganes... Jugamos básquetbol y patinamos..

Sentí que las personas necesitan divertirse, necesitan la belleza y los colores vivos, como este parque cultural...” (Hockney y Stangos, 2002).

El argumento narrativo del Parque de los Colores, su estética inicial y su inspiración, tienen origen en el texto anterior y en los cuadros del libro de Hockney That is the way I see it. Lo que a Miralles le interesaba era el ambiente, el entorno en que estos cuadros y esta historia rondaban en su cabeza. El programa del parque era el mismo, una coincidencia que detonó su imaginación y activó la memoria sensible de Miralles... "lo demás es pura plástica". Los cuadros de Hockney pasan a ser trazas de Miralles, que serán trans- formados en pavimentos de hormigón de color, piletas de agua, asientos y pistas de skaters... como las del parque cultural de Cantón en China. "Podríamos contar este parque sólo con los cuadros de Hockney, darían una visión de lo que pasaba por la cabeza de Miralles a la hora de empezar a proyectar" 6 . En el acceso norte del parque están las piletas de agua más grandes, sinuosas, azules y con tubos de acero inoxidable que forman sus chorros de lluvia; son las Montañas de Kweilin del libro de Hockney, transformadas en el agua del parque. Sus tubos suspendidos como agua circulando son la fotografía de un momento.

V. ESTRUCTURAS SUPERPUESTAS / "Así el primer modelo fueron los muros perimetrales que se elevan desde el suelo". La idea de elevar los muros corresponde a la idea de modificar los límites del sitio y dejar en el nivel de la calle un parque continuo, donde se pueda pasear libremente y atravesar de un punto a otro sin esquivar las construcciones. Al mismo tiempo, por medio de las sombras, se buscaba dar una noción de lugares temporales de juego. Estas estructuras conforman el escenario interior y exterior del proyecto. Su presencia iconográfica caracteriza al parque: son las formas más visibles, representativas y las más recordadas. Sólo por estar elevadas las percibimos más dinámicas, cambian de posición, de escala y hasta desaparecen cuando caminamos por debajo de ellas.

Distinguimos varios tipos de estructuras superpuestas que responden a operaciones de conceptualización y de diseño diversas. Primero, en los muros de ladrillo sobre pilares de hormigón, Miralles propone un reemplazo conceptual, pero también formal de los límites del parque; en este caso los muros de ladrillo tienen una doble lectura. Vistos desde el interior del parque tienen el mismo color y textura de los edificios que están en los alrededores, y vistos por fuera son umbrales de acceso claros y contrastantes. En segundo lugar están además los grafitos o muros-letras sobre trípodes de hormigón, que representan la huella de una manifestación cultural: son el símbolo de la sociedad marginal, pero positivamente elevan los graffitis a un nivel de aceptación pública, valorándolos como una expresión existente en el lugar. Su tratamiento es un reconocimiento a los habitantes, una identificación y una apropiación; al estar elevados y desescalados, arrojan una sombra que es una imagen distorsionada y dinámica de ellos mismos, que cumple una doble función. Desde dentro del parque, al igual que los muros de ladrillos elevados, tienen el mismo color que su fondo, mezclándose cromáticamente con las casas. En el proceso de formalización de los grafitos, Miralles utilizó muchas fotografías de graffitis de las calles del sector y de otros sectores de la ciudad de Barcelona. Seguido a esto, se escribieron los nombres de los barrios Plana Lledó y Santa Rosa y el nombre del Parque en nuevos graffitis, los cuales Miralles desfiguró, borró, olvidó y finalmente trazó en lo que conocemos. Estos muros "representan el nombre del parque y de sus habitantes, representan las letras y las letras se confunden una sobre la otra y finalmente sólo sirven para protegerse del sol" (VV.AA., 2002).

Por último, los pilares de acero doblados y cintas colgadas de iluminación soportan líneas de luz, acompañando el recorrido de la gente que 

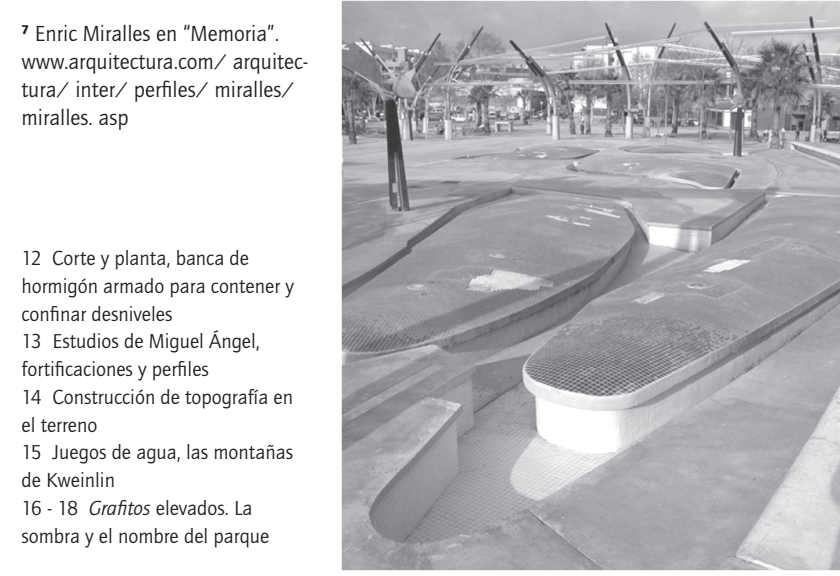

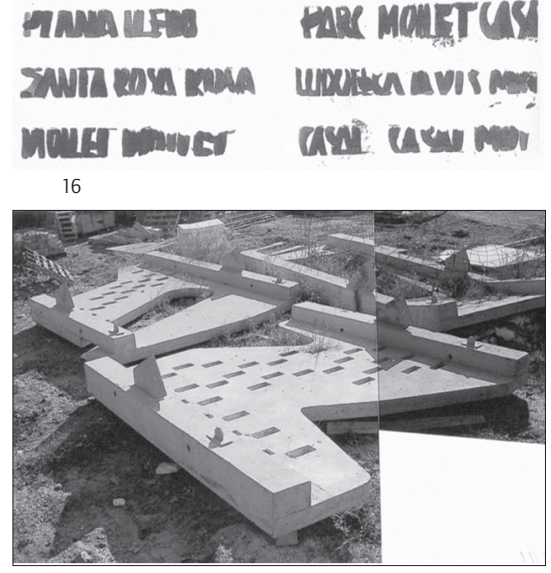

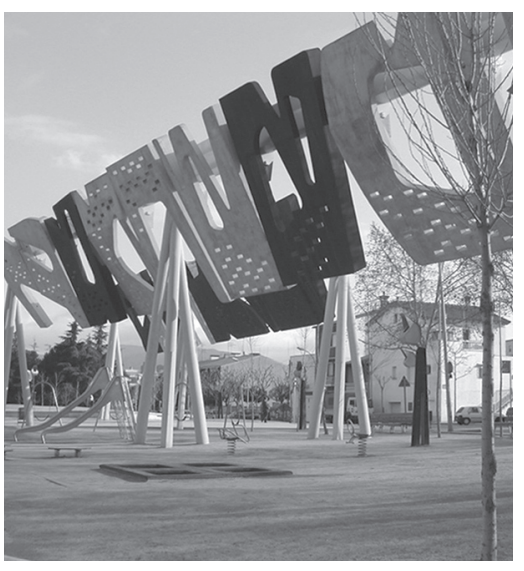

llega desde el centro la ciudad, marcando la diferencia entre llegar y estar en el parque. Igualmente, las lámparas de metal plegado y oxidado, desperdigadas por el parque, tienen el carácter de un personaje, son el habitante continuo del parque y forman parte de la familia de cosas que hacen irreal este lugar.

VI. LA VEGETACIÓN: EL TIEMPO, LUGAR EN DESARROLLO / La idea de lo incompleto en Miralles es recurrente como una manera, la única según sus propias palabras, de ver la arquitectura.

Las estructuras superpuestas del parque determinan un porcentaje de las sombras pensadas; éstas se completarán con el crecimiento de la vegetación y lo construido cambiará de escala, aumentando la percepción de interioridad y contención. Dejará de ser un parque precario por su falta de verde y de sombra natural; tendrá hojas en el suelo en otoño y se notará el aumento de las sombras en verano producto de la gran cantidad de árboles de hoja caduca puestos en el costado sur, hacia el recorrido del sol.

V. Conclusiones / El Parque de los Colores está inserto en el diálogo que toda la obra de Miralles tiene con el suelo y el paisaje, pero además con un matiz social. Si aceptamos que este parque reestructuró el concepto de los parques urbanos, tanto por la novedosa "visibilidad sensual de la representación", como por ser un objeto "designador al servicio de una memoria cultural" (Porphyrios, 1990), podemos decir que en este nuevo modelo existe un vínculo recíproco entre la imaginación y el recuerdo: unas relaciones reversibles en sus signos y en sus representaciones, "ofreciendo un nivel altísimo de cosas comunes, pero fuera de la tradición" (Miralles, 1992). "Un proyecto consiste en saber atar múltiples líneas, múltiples ramificaciones que se abren en distintas direcciones. Mi modo de trabajar está muy ligado a la idea de curiosear o de distraerse. Una vez fijado el problema, el siguiente paso es casi olvidarse de la finalidad de lo que estabas haciendo, casi como para distraerte..."”.

Miralles explica sus edificios a través de la continuidad entre cada proyecto: los esfuerzos anteriores le siguen interesando y un profundo vínculo recorre todos sus proyectos. "Cada proyecto tiene en sí mismo las características de los que le han precedido y los genes de aquellos que le seguirán" (De Michelis y Scinemi, 2002).

El proyecto del parque y todo su proceso, lo entenderemos como "un entrecruzamiento entre relato y lugar, virtual y real, visual y táctil, habitar $y$ construir; en pocas palabras, un escenario que nos permita 'redescubrir' la experiencia de jugar, saltar, pasear, reír, sorprendernos, imaginar y contemplar. Este espacio es una imagen tridimensional, caleidoscópica de su propio uso" (Muntañola, 1994).

El reemplazo de la topografía por otra artificial, entendida como el nuevo suelo -base conceptual y física del proyecto- donde se posan las representaciones sociales interpretadas por Miralles y materializadas en pisos de colores, agua, edificios elevados, caminos de luz, personajes y estructuras, es una manera de entender el Parque de los Colores, y es una forma de acercarse al proceso, a ese sistema de fuentes diversas, de temas paralelos e independientes que exploran con sus propias fuerzas las posibilidades y aportaciones que le dan al proyecto matices, complejidades y un sello original.

Es recordar y asociar fuentes de conocimientos de muchas procedencias, pero siempre por medio de un particular modo de ver las cosas: verlas como una manifestación cultural, y usarlas a favor de la arquitectura, una arquitectura capaz de poner a dialogar cosas que otros nunca vimos.

Decía Enric Miralles: "Yo afirmo lo siguiente: hay que llamar arquitectura no a los objetos construidos de acuerdo con unas ciertas técnicas y materiales, sino a un modo de imaginar". ARQ

\section{Bibliografía}

Ackerman, James. La arquitectura de Miguel Ángel. Celeste Ediciones, Madrid, 1997. / Arranz, Félix. “Pensar dialogado”. Block № 9, Universidad Torcuato Di Tella, Buenos Aires, 1989. / Cortés, Juan Antonio. "La geometría a muerto iViva la geometría!". Circo № 57. Cooperativa cultural Circo, Madrid, 1998. / De Michelis, Marco y Maddalena Scinemi. EMBT, MirallesTagliabue, obras y proyectos. Skyra Editore, Milán, 2002. / Hockney, David y Nikos Stangos (ed.). That's the way I see it. Thames and Hudson Ltd., Londres, 2002. / Lahuerta, Juan José. Documentos de arquitectura. Enric Miralles, obras y proyectos. Editorial Electa, Milán, 1996. / Lefaivre, Liane y Alexander Tzonis. Humanist rebel, Aldo van Eyck. 010 Publishers, Rótterdam, 1999. / Llorente, Marta. “Cuatro libros de Eugenio Trias”. 3ZU № 2. Revista d'Arquitectura ETSAB, Barcelona, 1994. / Márquez Cecilia, Fernando y Richard Levene (ed.). El croquis № 100-101. El croquis Editorial, Madrid, 2000. / Massad, Fredy y Alicia Guerrero. "La forma de lo imperfecto, impresiones de Enric Miralles". www.vitruvius.com.br. / Miralles, Enric. "Ès això de Jujol". Quaderns II № 178-180. Collegi d'Arquitectes de Catalunya, Barcelona, 1988. / Miralles, Enric. "On the trundling turk”. Arquitectura № 292. Colegio Oficial de Arquitectos de Madrid, Madrid, julio de 1992. / Miralles, Enric. "Memoria". www.arquitectura.com/ arquitectura/ inter/ perfiles/ miralles/ miralles.asp / Muntañola, Josep. Topogénesis uno: ensayo sobre el cuerpo y la arquitectura. Oikos-tau Editores, Barcelona, 1979. / Muntañola, Josep. Arquitectura: texto y contexto. Transcripciones II. ETSAB, UPC, KHÒRA № 13, 2001. / Muntañola, Josep. "Las estructuras de la memoria en la arquitectura de Enric Miralles”. 3ZU № 3. Revista d'Arquitectura ETSAB, Barcelona, 1994. / Porphyrios, Demetri et al. Eric Gunnar Asplund, estudios críticos 3. Editorial Stylos, Barcelona, 1990. / Restany, Pierre. Hundertwasser, el pintor-rey con sus cinco pieles. Benedikt Taschen Verlag GmbH, Colonia, 1999. / Ricoeur, Paul. "Arquitectura y narratividad". Arquitectonics № 4 Arquitectura y Hermenéutica. Edicions UPC, Barcelona, 2003. / Simmen, Jeannot y Kolja Kohlhoff. Kasimir Malevich, vida y obra. Könemann Verlag, Colonia, 1999. / Strauven, Francis. Aldo van Eyck. The shape of relativity. Architectura \& Natura Press, Ámsterdam, 1998. / Tomlow, Jos. "Some Gaudinist aspects in a work by Enric Miralles”. Gaudí № 10. Circular del Centre d'Estudis Gaudinistes, Barcelona, septiembre de 1998. / VV.AA. "Parc dels Colors". L' informatiu № 199. Col-legi d'aparelladors i arq. tecnics de Barcelona, Barcelona, febrero de 2002. 